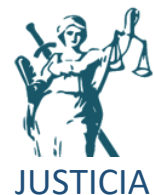

JUSTICIA

ISSN impreso 0124-7441

\title{
Carl Schmitt, Leo Strauss, Max Weber y el debate sobre la relación entre el orden político y los valores ${ }^{1}$
}

\section{Carl Schmitt, Leo Strauss, Max Weber and the debate on the relationship between political order and values}

\author{
Félix González Geraldino \\ Facultad Latinoamericana de Ciencias Sociales, Argentina \\ gonzalezgeraldino@gmail.com
}

Recibido: 8 de mayo de 2018 / Aceptado: 4 de septiembre de 2018 https://doi.org/10.17081/just.24.35.3389

\section{Resumen}

El siguiente artículo busca reflexionar en torno al problema de los valores y el orden político. Relegado por el pensamiento crítico, dichas problemáticas se muestran, en la cotidianidad, ineludibles. Esto nos lleva a una consideración del entrecruzamiento entre axiología y política. Entrecruzamiento del cual las obras de Max Weber, Carl Schmitt y Leo Strauss nos sirven como aportes. Negación de los valores, necesidad de los valores y mediación de los valores, serán los puntos sobre los cuales el articulo reflexionará teniendo en cuenta las posturas de estos autores.

Palabras Clave: valores, política, orden político, max weber, carl schmitt, leo strauss

\section{Abstract}

The following article seeks to reflect on the problem of values and political order. Relegated by critical thinking, these problems are shown, in daily life, inescapable. This brings us to a consideration of the intersection between axiology and politics. Cross-linking of which the works of Max Weber, Carl Schmitt and Leo Strauss serve us as contributions. Negation of values, need for values and mediation of values, will be the points on which the article will reflect taking into account the positions of these authors.

Keywords: values, politics, order político, max weber, carl schmitt, leo Strauss

\section{Como citar:}

González Geraldino, F. (2019). Carl Schmitt, Leo Strauss, Max Weber y el debate sobre la relación entre el orden político y los valores. Justicia, 24(35). 29-40. https://doi.org/10.17081/just.24.35.3389

I Esta es una versión revisada y carregida de la panencia "Carl Schmitt, Leo Strauss, Max Weber y el debate sabre los valores y la política", presentada por la autar en el XIII Jarnadas de Saciología que se llevarán a cabo en Buenos Aires, Argentina, del 22 al 25 de Agasto de 2017.

Justicia Vol. No. 35: pp. 29-40. Enero-Junio, 2019. DOI: 10.17081/just.24.35.3389

(C) Copyright 2019 by González Bolívar, D.

$$
\text { open } 2 \text { access (c) (i) }
$$




\section{INTRODUCCIÓN}

El pensamiento crítico tradicionalmente se ha situado enfrentado al poder. Por pensamiento crítico nos referimos, principalmente, al de izquierdas y, en el caso del poder, a cualquiera que esté institucionalizado $y$, mientras mayor sea, peor. En nombre de lo otro del poder, dicho pensamiento, a exaltado los momentos rupturistas, y discontinuistas. Elogio de lo discontinuo y ser lo otro del poder parece necesitarse mutuamente. La influencia, negativa, de los regímenes históricos puede explicar parcialmente este fenómeno. Al calor de regímenes marcadamente injustos se forjó dicho pensamiento para quien el poder institucionalizado era lo otro a enfrentar. En muchas de estas variantes la ruptura, la revolución, se justificaba en aras de un momento formativo posterior, sea este la dictadura del proletariado o una sociedad otra. Como fin inmanente, y único justificativo del usufructo del poder -de dicho momento formativo constitutivo- se encontraba la abolición de toda injusticia, la erradicación del poder de la esfera humana. Pensamiento crítico y poder se acercaron, paradójicamente, solo con la mutua promesa de separarse para siempre. Sin embargo, el carácter demasiado humano de los regímenes políticos instituidos, es decir, la no realización de su fin inmanente -la abolición de la injusticia y el paraíso en el más acá- conllevó una nueva separación entre, el ahora verdadero, pensamiento crítico y el poder. La injusticia visible del régimen llevó al retraimiento del pensamiento crítico en su relación con el poder. La eliminación del conflicto se develó como un lastre dogmático cayendo, así, la esperanza en un mundo completamente justo en el más acá. Si la unión de crítica y poder era justificada, otrora, en nombre de la sociedad sin contradicción, la imposibilidad de ésta, nos lleva ahora a su escisión definitiva. En la modernidad tardía, o posmoderna, el elogio de lo discontinuo alcanza su máxima expresión al negar todo momento de positividad².

Si esta visión ha sido la predominante y, como toda visión adolece de un punto de ceguera, es probable que la persistencia en determinados problemas -movidos por el hecho de ser lo otro del poder-impida la apreciación de otros. Esto es lo que ocurre con el problema del orden y los valores y el de su entrecruzamiento. Es que históricamente dicho problema ha sido asociado, con fundamentos, a un pensamiento conservador en términos políticos. Incluso ya en la propia denominación de un pensar crítico la idea de orden adquiere una innegable incomodidad. Así es que en el debate político contemporáneo encontramos, por ejemplo, posiciones dominantes donde la negatividad, paradójicamente, se vuelve la regla. La crítica se vuelve un elemento permanente, en tanto todo aquello que se mantiene detenta un sello de arbitrariedad, de parcialidad, de violencia e injusticia. La necesidad de la negación permanente lleva a la posición de un intelectual que sospecha absolutamente de todo, todo el tiempo. Así, entre otras cuestiones, se escinde la idea de derecho y la idea de justicia. El derecho instituido conlleva la marca de lo caído del mundo y, por ello, de la injusticia. Por ello, en tal decir, "no podemos acercarnos a la justica sino deconstruyendo el concepto que la confunde con el derecho, porque la justicia excede toda figura jurídica" (Yébenes, 2008: 120). Podríamos continuar con la misma idea sosteniendo que en tanto todo orden conlleva la misma marca de lo impuro, toda identificación con un orden es una identificación con la injusticia. Incluso una valoración, deja por sí misma, algo como no valorable, por lo cual, conlleva la misma marca de lo parcial. Como corolario, la distinción entre un derecho justo y otro injusto o entre un orden justo y otro injusto, se vuelve imposible Tras la vuelta

2 Un ejempla de dicho pensamienta, aunque se enfaca en la cuestión de qué es un intelectual es el artícula publicada en el númera diecisiete de la Revista de Política y Cultura Ideas de Izquierda de Eduarda Grüner, titulada "Dué (no) es un intelectual". Allí nos dice "el intelectual es dis-funcional e in-enrolable", "son los que ven en la cultura no su apariencia de orden estático, apolíneo y eterno sino su estado de crisis", ya que la cultura "está siempre en crisis". El problema es que "el poder tiene razones que la razón intelectual no entiende: ella está empeñada, como decíamos, en interrogar allí donde el poder necesita respuestas. Q en negativizar allí donde el poder demanda afirmaciones". Por ello "el primer impulsa de un intelectual es criticar al poder[.] a cualquier poder". El problema, desde nuestro punta de vista, es que, siguienda a Nietzsche, lo apolíneo no puede rechazarse en tanto tal y, en cierta medida, no solo es necesario, sino, saludable.

Justicia Vol. No. 35: pp. 29-40. Enero-Junio, 2019. DOI: 10.17081/just.24.35.3389 
al mundo a caballo de la crítica llegamos, incluso, a la conclusión de que "la política de la deconstrucción no se deja asimilar al pensamiento revolucionario [ya que], hay algo conservador en toda revolución[,] la deconstrucción en cambio se resiste a ser alineada" (Ibídem: 120) La negatividad, así, alcanza y supera al proceso político eminentemente negativo: la revolución. Es que tras esta, un momento de conservación es indispensable. Al final, el punto de llegada del movimiento es el mismo que el de partida: un criticismo puro que, en aras de no contaminarse con el mundo caído, permanece inmóvil criticándolo todo. Así, la incapacidad de distinguir entre órdenes justos e injustos -ya que todos son, en tanto ordenes, injustos-nos lleva a un retraimiento del mundo al estar, este, ya signado por la caída.

No es casualidad que, en otro contexto, dicho pensamiento que todo lo niega no haya permeado con tanta facilidad. Las, no tan nuevas y ya duraderas, experiencias latinoamericanas posneoliberales llevan a experimentar, en ciertos pensadores críticos, la necesidad de conservar algo. Es que si la distinción entre un orden más justo que otro es posible, algo puede merecer ser conservado. Sin embargo, en ciertas ocasiones ese sentimiento no es acompañado por una reflexión teórica acabada, escindiendo así la teoría y la práctica. Mantener una posición teórica que eleve únicamente lo discontinuo nos obliga, si es que lo hacemos, a que las toma de posición a favor de un poder de turno sea de la índole de lo inexaminado y, por ello, arbitrario. ¿Es posible conciliar poder y crítica de una manera que no sea, solamente, mediante la crítica del poder? y si otra manera es posible, ¿nos llevaría esto a eliminar toda crítica al poder?

En este sentido es que el problema del orden justo adquiere relevancia. Lo adquiere en el entrecruzamiento, no exento de problemas, de sus dos partes: aquella que enfatiza el orden y aquella que enfatiza el valor. La posibilidad, experimentada usualmente, de juzgar entre órdenes más justos que otros nos llevan a la necesidad de plantear el interrogante por lo valioso en sí. A sabiendas también de que el mundo definitivamente justo no es posible, la pregunta por el orden adquiere relevancia y la pregunta por lo justo en abstracto debe hacer las paces con sus propias condiciones de posibilidad. En determinado momento, aun conscientes del carácter parcial de toda institución, la identificación entre derecho y justicia parece pertinente y, su conservación, necesaria. La separación, a priori, entre crítica y poder en nombre de la injusticia de todo lo existente, nos hace no solo incapaces de reflexionar sobre las diferentes realizaciones del poder ${ }^{3}-$ abandonando, por ello, nuestras distinciones a la esfera de lo arbitrario- sino también impotentes para la participación activa en el mundo. Incapacidad de reflexionar en torno a nuestras distinciones e impotencia práctica son los corolarios de la pureza de la crítica.

Hasta aquí el problema podría ser resuelto, si la pregunta por la posibilidad de juzgar racionalmente los regímenes políticos encontrara una respuesta afirmativa. Pero, de forma inmediata, esto no es evidente. La necesidad político-práctica de juzgar entre órdenes más valiosos que otros nos llevan a la necesidad de interrogar los valores que informan esos juicios. Constatar que el mundo definitivamente justo no es posible, no equivale a desmentir la necesidad de reflexionar de manera sistemática sobre el valor de los órdenes políticos. Ahora bien: ¿cómo restituir la pregunta teórica por el valor del orden político sin caer en una teoría política partisana? ¿Es posible encontrar un punto medio entre la incapacidad de distinciones valorativas, y por ello el relativismo de los valores, y el fundamentalismo del valor? Estas interrogantes no son, en sí mismas, novedosas. Replican casi exactamente el problema postulado por Max Weber en torno a la existencia de múltiples dioses y demonios y a la imposibilidad de una elección objetiva. Postulado que, en la actualidad, el pensamiento posfundacional replica de manera similar. Tanto

3 Lo que implica entender que las formas objetivadas del poder san plurales, existienda, a su vez, relaciones conflictivas entre las mismas. Si dejamos de entender al poder existente como una magnitud manacorde y tomamos conciencia de su existencia en conflicto, el ser la otro del poder se vuelve imposible. 
Carl Schmitt como Leo Strauss volvieron sobre este problema weberiano, intentando restituir una latitud teórica que permitiera reflexionar sobre el valor de los órdenes políticos. La actualidad del problema weberiano justifica, en suma, el recurso a las reflexiones de Schmitt y Strauss. Por ello, el siguiente texto trabajará en torno al problema del orden político y los valores atravesando las obras de Max Weber, Carl Schmitt y Leo Strauss.

El texto estará dividido en cuatro apartados. El primero restituirá el estado actual de la cuestión, es decir, el impasse weberiano replicado de forma similar por el pensamiento posfundacional. Tras restituir este impasse, consistente en la imposibilidad de realizar juicios de valores objetivos y, por ende, en el abandono de su reflexión, el segundo apartado buscará, a través de Carl Schmitt y Leo Strauss, el recorrido que nos lleva a dicho punto de llegada. La neutralización y privatización de los valores fruto del liberalismo aparecen como el principal determinante de un proceso, iniciado en la modernidad, que concluye en la renuncia teórica del problema de la valoración de un orden y se su mantenimiento. Si este apartado concluye con la negación de los valores, el siguiente restituye su necesidad. Así, el tercer apartado apuntará a problematizar dicha negación al admitir que la indagación del orden justo es un componente ineluctable de la política. El último apartado se centrará en las soluciones bosquejadas por Schmitt y Strauss al problema del entrecruzamiento entre orden político y valores. Esto implica una consideración detenida en experiencias pre-modernas que marcan el camino de la superación del problema de la modernidad: en el caso de Strauss el renacimiento de la filosofía política clásica y, en el caso de Schmitt, la reposición de la Iglesia católica como forma política ejemplar.

\subsection{El impasse actual y su planteamiento en Weber}

El problema de los valores es tratado, en la actualidad, bajo la pregunta por el fundamento. En EI pensamiento político posfundacional de Olivier Marchart podemos encontrar el horizonte actual de la discusión. El posfundacionalismo vendría a revelar la diferencia ontológica entre lo político y la política. Revelación que nos recordaría del carácter abisal de toda fundación y de, a su vez, necesidad. El posfundacionalismo constataría, así, la existencia de los más variados fundamentos, la imposibilidad de elegir uno sobre otro y la necesidad de la contingencia entre ellos. A su vez, y delimita la pauta a seguir para el estudio posfundacional, el problema de la política necesita de una investigación ontológica. La comprobación de la precariedad de la institución política, y del fundamento que la legitima, nos llevaría a una indagación profunda del aspecto ontológico de lo político. Ahora bien, este punto de llegada en relación al orden y los valores -o fundamentos- no es, en sí mismo, novedoso. Replica casi exactamente, con otras palabras y conceptualizaciones, el problema de Max Weber de la existencia de múltiples dioses y demonios, y de la imposibilidad de una elección respaldada entre ellos. Incluso el mismo Marchart -luego de afirmar que la constatación del carácter contingente "conduce a una situación donde las afirmaciones de valor contrapuestas ya no pueden recurrir a un principio superior"- lo reconoce: "Nos encontramos pues, en el campo de batalla de los dioses guerreros de Max Weber" (Marchart, 2009: 48). Así la afirmación weberiana de la distinción entre hechos y valores y, por consiguiente, la incapacidad de una indagación objetiva de los valores se replica en el pensamiento posfundacional. Como nos dice Marchart, "de la ausencia de fundamento no se desprende ninguna consecuencia política necesaria" (Ibídem: 17). En otras palabras, la inmersión en los profundos meandros de la ontología no nos puede indicar una dirección política específica.

No obstante esto, la valoración ocurre, pero de forma subrepticia. La afirmación de una ontología de lo múltiple, donde todo lo que existe merece perecer -nos dice Marchart- "puede conducir a la creciente aceptación de la contingencia, de la historicidad del ser, la cual tiene, potencialmente, un efecto liberador" (Ibídem: 206). Incluso asevera -luego de aclarar que no constituye un juicio de valor- que "la democracia es el régimen que está más dispuesto a aceptar 
la ausencia de un fundamento último" (Ibídem: 208). Si inmediatamente la ausencia de fundamento no nos puede indicar una normatividad política, luego, indirectamente, una política liberadora y democrática sería más acorde a dicha ausencia. Esta forma subrepticia de valoración consiste en realizar una equiparación, no admitida, entre cierta ontología y cierto correlato óntico. La afirmación de Laclau de que la política, en sentido eminente, es populista (Laclau, 2009: 195) no es más que una variación de esta constante. De este modo, la renuencia posfundacionalista a valorar un orden político en detrimento de otros incurre en una valoración indirecta e inexaminada. Ante, no reflexivo de esta toma de posición, la pregunta por el orden valioso, por el entrecruzamiento entre orden político y valor, se demuestra necesaria.

En la actualidad asistimos a un impasse: una constatación trágica de la lucha irresoluble entre valores contrapuestos. De la constatación de la existencia de múltiples fundamentos a igual medida, se deriva la imposibilidad de respaldar la elección de un valor sobre el otro ${ }^{4}$. Sin embargo, como sostuvimos antes, dicho impasse no representa novedad alguna, es el mismo punto al de Max Weber arriba a principios de siglo. Para Weber la relación que se da entre el individuo y su valor político es del orden la fe. Reminiscencia secularizada de la religión, el individuo debe elegir entre dioses y demonios. En tanto el acto está marcado por un salto de fe, la razón no nos puede dar una jerarquía de fines. Se asiste, así, a la existencia de una multiplicidad de divinidades enfrentadas entre ellas sin más respaldo que la fuerza subjetiva del arrojo. La ciencia, la indagación racional moderna, no es, en el fondo, diferente a otra elección. Tan irracional como cualquier divinidad, el sustento de la ciencia es la fe en la misma. Este diagnóstico weberiano, ha sido catalogado tanto como un relativismo, en tanto todos los valores tienen, potencialmente, la misma valía y ninguno existe por fuera del mundo histórico y, a su vez, de absolutismo en tanto la relación del individuo con el valor es absoluta, no existiendo, entre dioses, diálogo alguno.

El acto de fe que media entre el individuo y el valor político no es la única influencia de la religión en la política, incluso en un contexto secularizado, desde la óptica de Max Weber. Los tres tomos de sus Gesammelte Ausfätze zur Religionssoziologie dan cuenta de otro motivo del entrecruzamiento entre lo religioso y lo político-social. Allí, Weber da cuenta cómo los diferentes modos de acceso a lo divino, principalmente la vía mediante la cual se obtiene la redención, hacen a diferentes modos de comportamiento (Lebensführung). La sistematización (sea alta o baja) y el tipo de conducta, junto a la mentalidad que fomenta, se modifican rotundamente si tenemos la posibilidad de redimirnos parcialmente mediante la confesión de nuestros pecados que si esta no es posible y, en cambio, debemos dar cuenta a cada momento nuestra calidad de asistidos por la divinidad. Esto implica que la relación con lo divino no se da de forma unívoca. Según esto, todo parecería indicar que si existen diferencias relevantes en el modo de acceso a lo divino que repercuten en la forma en que el acto de fe, en tanto tal, se da, nada nos impediría pensar que el vínculo con el valor político, que se da mediante un acto de fe entre dioses y demonios, puede darse de modos disímiles. No obstante esto, el individualismo metodológico de Max Weber le impidió poder pensar dicha relación más allá del arrojo subjetivo de cada individuo. Si la experiencia de las religiones nos permite extraer que el vínculo con lo divino no se da de un solo modo, ¿por qué el vínculo con el valor político es siempre individual? En su deuda con la modernidad, de corte protestante -que ve la relación con Dios, principalmente, en términos individuales- Weber se encuentra en un callejón sin salida: partiendo del individuo como dato primero nuestro corolario debe ser la constatación teórica trágica de la existencia de múltiples dioses y demonios y su existir en conflicto.

4 En el artícula "Cué (no) es un intelectual" Eduarda Grüner parece llegar a la misma conclusín que escinde el plano teórica del plano de la postura valorativa. Para Grüner, el intelectual puede tomar una pastura política "afiliarse a apayar a un partida, movimienta o agrupación política, inclusa un gobierno: pero no la hace en tanta intelectual, sino como sujeto, como militante". Se debe escindir entre el sujeta militante y el sujeto tearizante. Una vez más, como corolario, una tearía impotente y una práctica potenciada irracionalmente.

Justicia Vol. No. 35: pp. 29-40. Enero-Junio, 2019. DOI: 10.17081/just.24.35.3389 
Por ello es necesario dirigirse tanto a Leo Strauss como Carl Schmitt -autores cuya formación se dio en el marco de la indagación de los valores por parte del neokantismo y, ambos, marcados por la influencia de Weber. Sus aportes resultan pertinentes para contribuir a la reflexión general al problema del entrecruzamiento entre orden político y valor. Si la conclusión weberiana se explica, en parte, por su lastre moderno, la crítica a la modernidad aparece como la condición sine qua non, para avanzar en el problema de los valores en la política. Creemos que, a su vez, los caminos seguidos por Schmitt y Strauss no solo nos permiten ir más allá del impasse producido por la constatación trágica, sino, también, que encarnan una vía de problematización que pondera, a su vez, el problema político concreto. Es decir, que producen una contribución significativa al espacio político público. Contribución que la reflexión ontológica, ensimismada en sus categorías crípticas acordes al nivel de profundidad que pretenden, pierde de vista.

\subsection{Genealogía del impasse}

Tanto Carl Schmitt como Leo Strauss observan, en la modernidad, una tendencia creciente hacia la negación del problema político fundamental. Para el primero la modernidad implica un proceso de neutralización y despolitización, que encuentra en la fe en la técnica como condición de posibilidad una vida pacífica su punto más álgido. La negación de lo político implica, así, su reducción a un problema técnico. Progreso técnico mediante, el paraíso en el más acá se volvería posible dando comienzo a la paz universal y erradicando todo tipo de conflicto. La lucha eminente se transforma, para quienes niegan lo político, "por el lado económico, en competencia, y por el lado "espiritual», en discusión [y] en lugar de la distinción clara entre los dos estados opuestos de "guerra» y "paz» aparece aquí la dinámica de la competencia eterna y de la eterna discusión" (Schmitt, 2014: 101).

Desde la óptica schmittiana la modernidad da lugar al giro hacia la esfera privada, al pasaje hacia la prioridad del individuo. Continuando y complejizando la tesis weberiana del rol del protestantismo en la modernidad, el protestantismo significa, para Schmitt, la privatización de la religión. Por ello, sostiene irónicamente que para el protestante, "sería más correcto rezarle con un "padre mío» que con un "padre nuestro»" (Schmitt, 2011: 55). No es casualidad, para el Jurista de Plettenberg, que de la privatización de la religión se pase a la religión de lo privado. Como corolario de la modernidad, en un lenguaje que recuerda al de Weber, "en vez de la Iglesia visible, aparecería una iglesia de lo visible, una religión de una palmaria materialidad" (Ibídem: 68). Incluso en La dictadura, de 1921, Schmitt -introduciendo las dos oposiciones más grandes en la teoría política, aquella que hace del individuo dato primero y aquella que lo muestra deudor del Estadopone en paralelo el giro hacia el individuo y el protestantismo, en este caso, puritano: "En las manifestaciones de Locke, la influencia procedente del cristianismo puritano es todavía bastante fuerte para resaltar, por encima de toda duda, la individualidad concreta y sustancial" (Schmitt, 2013: 128).

Desde la óptica de Teología Política el proceso de neutralización y despolitización está en relación con la tendencia inmanentizadora, también moderna. Esta tendencia hace alusión al olvido del factor trascendente legitimante de toda ordenación. Este factor trascendente, o idea jurídica, representa para Schmitt una distinción sobre lo justo y lo injusto, a través de la cual el Estado hace el pasaje de la cantidad (poder) a la cualidad (derecho). Negación de lo político, olvido de lo trascendente, privatización del valor, son el corolario del proceso moderno que encuentra en la realización del paraíso en el más acá, en la paz universal, fe en la técnica mediante, su objetivo fundamental. 
En el decir de Leo Strauss la búsqueda de la paz y comprensión, la eliminación de todo conflicto eminente implica "renunciar por completo a la cuestión de lo correcto para ocuparse únicamente de los medios" (Strauss, 2008: 162). Es decir, la posibilidad de la pacificación y la neutralización es posible a costa de la anulación de la distinción entre lo justo y lo injusto a la par de la reducción del problema político al del problema técnico, de los medios. Este silencio sobre la pregunta de lo correcto hace a la crisis de la modernidad. El hombre moderno tiene al alcance los medios más eficientes pero "no sabe ya lo que desea, [ya que] no cree que pueda conocer lo que es bueno y malo, lo que está bien y lo que está mal" (Strauss, 2011: 52). En la Ciencia y la Historia, encuentra Strauss, la razón de esta imposibilidad. Es que la distinción entre hechos y valores propios del cientificismo positivista, supone la degradación de toda indagación valorativa en relación con la pesquisa fáctica. Mientras la segunda puede adquirir el rótulo de científica, la primera lleva la marca de la subjetividad del individuo. A su vez, el descubrimiento de la historicidad de lo dado, el hecho de ser históricamente variable, hace imposible responder a la pregunta sobre lo que está bien y lo que está mal al ser, la noción de lo correcto, como todo, igual de histórica y variable. Como resultado, llegamos a la constatación de Max Weber -quien conjuga cierto historicismo con cierto cientificismo- para quien "hay una variedad de valores de igual rango, cuyas demandas entran en conflictos mutuos, que no pueden ser resueltos por la razón humana" (Strauss, 2014: 99)

En resumen, en el desenlace de la modernidad encontramos que "lo real es siempre individual" (Strauss, 2014: 95). Este individualismo liberal, encuentra como corolario una privatización del problema del valor y, así, una neutralización política. Es que si cada uno es el último juez acerca de lo justo, toda interrogación por lo justo encuentra en la inconmensurabilidad de lo individual, su punto límite. De esta manera, la modernidad liberal supone, a los ojos de Schmitt y Strauss, una negación del problema político fundamental y del interrogante político por excelencia. Dicha negación, se ancla en la fe en la técnica y en la privatización del valor.

\subsection{Más allá del impasse}

No obstante esto, lo político, para Schmitt, y la valoración, para Strauss, son ineludibles. Por ello, a la constatación trágica debe seguirla la consciencia de su necesidad. La conciencia del carácter necesario de lo político y la valoración es el primera paso para ir más allá del impasse. Quien niega lo político en aras de cierta neutralidad solo logra una acción política de mayor intensidad y, a su vez, deshonesta. La guerra final por la paz, que enfrentaría a los neutrales frente a quienes afirman el conflicto es solo la utilización de conceptos que buscan oscurecer lo político mismo. A fin de cuentas, lo político es el destino. Este carácter ineluctable del conflicto se asienta, en Schmitt, en una concepción antropológica negativa del hombre. El hombre es un peligroso, caído. Esto, no obstante, no implica concepción belicista de lo político o una admiración estética del conflicto. La maldad del hombre puede ser parcialmente neutralizada. Para Strauss, aun negada la posibilidad de realizar juicios de valores objetivos, nos enfrentamos, en nuestra vida diaria, con la necesidad de realizar acciones sustentadas en distinciones valorativas. Esto nos lleva, por lo menos, a una atenuación del rechazo de los juicios de valor y una restitución del problema del derecho natural. De forma independiente a nuestro querer, "toda acción política está guiada por algún pensamiento sobre lo mejor o lo peor" (Strauss, 2014B: 78). El carácter necesario del derecho natural no hace sin embargo a la posibilidad de satisfacer esa necesidad. Es decir, la apertura de la cuestión del derecho natural no implica, necesariamente, su clausura. Es que, en tanto el hombre es el único animal abierto a la pregunta por lo justo (Strauss, 2008: 162) la posibilidad de llegar a un punto final sobre dicha discusión no parece posible. Sin embargo, debe encontrarse una posición media entre el rechazo fanático del derecho natural y su abrazo, igualmente fanático (Strauss, 2014A: 65). 
La posible imposibilidad de clausurar la pregunta por lo justo, nos lleva a retrasar la afirmación universal del valor. El fanatismo aparece como la contrapartida posible de la restauración del derecho natural. La tendencia agresiva de las distinciones morales es un tópico constante en la obra de Schmitt, por lo menos desde El concepto de lo político hasta La tiranía de los valores. Es que lo moral funciona, también, como velo de lo político sin poder hacer más que intensificarlo. La subordinación de lo político a lo moral conlleva a la concepción de la diferencia política como diferencia moral. Dado este paso, la asimilación del enemigo político como "malo" legitimaría toda pretensión de su eliminación. Por ello, la reflexión de Schmitt en torno al problema de los valores resulta ambigua. Es que, si en un primer momento, afirma la relación intrínseca entre política y moral (Schmitt, 2011b: 20), luego, la búsqueda de la autonomía de lo político, la comprobación de los funestos efectos de la moralización de la guerra y la constatación de la "tiranía de los valores" lo conducirán a afirmar la separación tajante entre ambos (Schmitt, 2010). Precisamente, la crítica de Strauss a Schmitt orbitará en torno a la ambivalencia schmittiana respecto de la relación entre política y moral, dando lugar a un productivo diálogo (Strauss, 2008).

La ambigüedad de la postura schmittiana puede morigerarse si nos atenemos a las respectivas características de la moral postulada como necesaria para la subsistencia de toda ordenación y la moral criticada por sus ingentes efectos destructivos. Si la primera se caracteriza por el hecho de ser particular y encontrar asidero en el Estado como ámbito de lo general, la segunda está marcada por su carácter universal y encuentra su sostén en el individuo abstracto. La posibilidad del pluriverso político remitiría a la renuncia de la moral con pretensiones universales más no a una ética estatal o un trasfondo valorativo nacional. Se explica así, como, aun luego de la aparición de la crítica a la moral universal liberal, Schmitt sigue sosteniendo la necesidad de una ética estatal en "Ética de Estado y Estado pluralista" y una Constitución sostenida en valores frente a la neutralidad axiológica de la visión liberal que, a los ojos del Jurist, solo llevaría a la ruina de Weimar -como afirma en el final de Legalidad y legitimidad. En la crítica de la visión liberal de la moral parecería encontrarse los pasos a seguir para analizar la relación entre axiología y política. No obstante esto, dicha reflexión no fue formulada, de forma abierta, por Carl Schmitt. Es este, exactamente, el punto que Strauss en su comentario enfatiza: "Schmitt no se separa de la concepción de la moral de sus adversarios, y al no cuestionar la pretensión de la moral humanitaria y pacifista a ser la moral, queda atrapado en la concepción que él mismo combate" (Strauss, 2008: 164).

Si la neutralidad valorativa se vuelve imposible, y la afirmación del valor, problemática, debemos encontrar otras vías de reflexión ajenas a aquellas tomadas por la modernidad. Es que si la modernidad está signada por un continuo intento de neutralizar lo político, un ocultamiento de la pregunta sobre lo correcto, una degradación de los asuntos humanos a un problema técnico y una religión de la ciencia, un retorno, no exento de problemas, hacia lo pre moderno aparece, en el horizonte, como la condición de posibilidad de superar la crisis de la modernidad y la negación de lo político. En el caso de Carl Schmitt, al proceso de racionalidad técnico-instrumental creciente debe oponerse "la única racionalidad esencial, la racionalidad del fin" (Schmitt, 2011A: 19). En la Iglesia católica, como réplica de la encarnación de Cristo, encuentra el prototipo de dicha racionalidad. Esto implica, la aceptación de la necesidad de una dimensión ideal, metafísica, como plano legitimador de toda ordenación. Esto conlleva que "el principio vital en el ámbito del derecho es la justicia de la argumentación jurídica", es decir, el "juicio sobre la rectitud de los fines" (Schmitt, 2011B: 17). Supone esto, que la subsistencia de toda ordenación acaece porque "se impone el punto de vista mejor que obliga a las personas no por ser el más fuerte sino el mejor" (Ibídem: 20). Este reconocimiento de la idea jurídica, del elemento metafísico, se conjuga con el elemento fáctico encarnación mediante.

Justicia Vol. No. 35: pp. 29-40. Enero-Junio, 2019. DOI: 10.17081/just.24.35.3389 
El Estado, al Igual que la Iglesia es quien debe realizar en la facticidad del mundo el elemento ideal. Encontramos, entonces, no solo la afirmación de la idea jurídica sino la necesidad de una mediación institucional para realizarla. Cierta valoración se torna necesaria para mantener todo orden, pero dicha valoración no es inmediata al mundo, necesita una mediación institucional. Mediación institucional que implica, también, una relación con el valor no individual, sino colectiva. Se sostiene, por ello, que en la obra de Schmitt se encuentran aportes para un concepto de lo moral que supere la visión liberal, aun a costas de su no clarificación por parte del autor.

En el caso de Strauss, la vía alternativa a la modernidad resulta de la restitución de la filosofía política clásica. Ésta, en primer lugar, estaba íntimamente conectada con la vida política de la ciudad. En esta ligazón con la vida política descubre la existencia de posiciones encontradas en torno a lo bueno y lo justo (Strauss, 1970, 106). Sin embargo, éstas, tienen el carácter de opinión, en otras palabras, carecen de una reflexión detenida de su propia posición. Dicha reflexión, que es de índole filosófica, nos debe orientar a obtener un conocimiento ya no del estatuto de la opinión de lo bueno y lo justo. La filosofía política clásica consiste, de esta manera, en la reflexión acabada sobre la buena sociedad. Ahora bien, la filosofía política necesita torcerse en dos direcciones ateniendo a cada una de las palabras que forman su concepto. Si por un lado "la filosofía consiste esencialmente no en la posesión de la verdad, sino en la búsqueda de la verdad" (Strauss, 2014B: 80), deviniendo así, por su carácter zetético, un interrogar continuo, por el otro, el filósofo debe recordar su pertenencia a la ciudad como condición de posibilidad, incluso, de su mismo filosofar. Su anclaje político lo obliga "a hacer que el enfrentamiento civil cese y promover, a través de la persuasión, el acuerdo entre sus ciudadanos" (Strauss, 1970: 108). El peligro de su desunión, constituye una de las reflexiones centrales de la filosofía política clásica (Ibídem: 113). Esta bifurcación de los caminos de la filosofía política tiene como corolario una bifurcación de los modos de escritura. Marcado por el reconocimiento del carácter netamente destructivo de la filosofía, debe desarrollar una prudencia tal que conlleva a una doble escritura, por un lado exotérica y por el otro, esotérica. A su vez, dicha indagación está acompañada por un reconocimiento de la separación entre lo ideal y su realización. Esto implica entonces que, a pesar "de que cualquier orden realmente existente podía ser mejorable" toda introducción de un ideal de justicia debe ser prudente; es decir, mediado. "La justicia común debe ser «completada», corregida, [pero] nunca puede ser suplantada" por la justicia ideal (Strauss, 2014C: 169). Entre la justicia existente y la natural, debe haber una mediación.

\section{CONCLUSIONES}

De este modo, la puesta en diálogo de las obras de Carl Schmitt y Leo Strauss permite interrogar de manera productiva el problema de la relación entre orden político y valores, describiendo las dificultades de su elaboración moderna, señalando su lógica ineluctable y reflexionando sobre las condiciones institucionales de su restitución. En sentido estricto, la conclusión general de este articulo sostiene que Carl Schmitt y Leo Strauss demuestran que, más allá de las tendencias modernas a la neutralización, las valoraciones resultan una dimensión ineluctable de los órdenes políticos, al tiempo que señalan la necesidad de una mediación institucional de los valores, ya sea por vía teológico-política o filosófico-política. Ésta conclusión general puede desagregarse en una serie de puntos:

1: Tanto Carl Schmitt como Leo Strauss asocian la crisis de la modernidad a la neutralización de lo político, fruto de la fe en la técnica y la privatización del valor.

Justicia Vol. No. 35: pp. 29-40. Enero-Junio, 2019. DOI: 10.17081/just.24.35.3389 
No obstante estos esfuerzos modernos de neutralización de lo político, el problema de la valoración resulta inerradicable de la esfera pública. Esto exige la puesta en escena del entrecruzamiento entre política y axiología. Aquí, una vez más, las obras de Strauss y Schmitt permiten ganar claridad. En esta línea, nuestro segundo punto sostiene:

2: Carl Schmitt y Leo Strauss demuestran de maneras contrastantes la inerradicabilidad de las valoraciones en política, al tiempo que contribuyen al señalamiento de su carácter problemático.

En el caso de Strauss, esto equivale a un doble movimiento de restitución del interrogante por el derecho natural y de resguardo respecto de toda tentación de darle una respuesta definitiva. De manera análoga, pero claramente distinguible, para Schmitt, la apertura de la política a una idea trascendente de bien encuentra su contrapunto en los efectos tiránicos de los valores. Del doble carácter ineluctable y problemático de los valores en política, surge una tercera subhipótesis:

3: Carl Schmitt y Leo Strauss afirman la necesidad de la mediación entre valores y política, asumiendo perspectivas contrastantes respecto del modo institucional de esa mediación.

Esta mediación parte del reconocimiento de la distancia entre el ideal valorativo y su realización efectiva [Verwirklichung], asumiendo en cada caso una deriva singular y contrastante. En el caso de Schmitt, está mediación encontrará su modelo en la forma teológico-política mientras que, para Strauss, la reflexión sobre la mediación será conducida al horizonte de la filosofía política clásica.

\section{REFERENCIAS}

Grüner, E.. (2015), “Qué (no) es un intelectual”, Ideas y Debates. Recuperado de: http://www.laizquierdadiario.com/ideasdeizquierda/wpcontent/uploads/2015/04/24_ 26_Gruner.pdf

Laclau, Ernesto. (2009) El pueblo, lo popular y el populismo en: Pensando el mundo desde Bolivia: I ciclo de seminarios Internacionales. La Paz: Bolivia. Vicepresidencia del Estado Plurinacional, p. 177-196

Marchart, Oliver. (2009) El pensamiento político posfundacional: La diferencia política en Nancy, Lefort, Badiou y Laclau. . Fondo de Cultura Económica, Buenos Aires, Traducción de Marta Delfina Álvarez.

Schmitt, Carl. (1966). Teoría del partisano. Acotación al concepto de lo político. Madrid: Instituto de Estudios Políticos. Universidad de Antioquia Traducción de Anima Schmitt de Otero.

Schmitt, Carl. (1985). La dictadura. Desde los comienzos del pensamiento moderno de la soberanía hasta la lucha de clases proletaria. Madrid: Alianza. Traducción de José Díaz García.

Schmitt, Carl. (1990). Sobre el parlamentarismo, Madrid: Tecnos

Schmitt, Carl. (2000). Romanticismo político. Quilmes: Universidad Nacional de Quilmes. 
Schmitt, Carl. (2009) Teología política. Madrid: Trotta.

Schmitt, Carl. (2010) La tiranía de los valores. Buenos Aires: Hydra.

Schmitt, Carl. (2011 a) Catolicismo romano y forma política. Madrid: Tecnos.

Schmitt, Carl. (2011 b) El valor del Estado y el significado del individuo. Madrid: CEPC.

Schmitt, Carl. (2011 c) "La visibilidad de la Iglesia" en Catolicismo romano y forma política. Madrid: Tecnos

Schmitt, Carl. (2014) El concepto de lo político. Madrid: Alianza.

Strauss, Leo. (2008) "Comentario sobre El concepto de lo político, de Carl Schmitt" en Meier, Heinrich (comp.) Carl Schmitt, Leo Strauss y El concepto de lo político. Buenos Aires: Katz.

(2014 a) “¿Qué podemos aprender de la teoría política?” en ¿Qué es filosofía política? Y otros ensayos. Madrid: Alianza.

(2014 b) Derecho natural e historia. Buenos Aires: Prometeo.

(2014 c) ¿Qué es filosofía política? y otros ensayos. Madrid: Alianza 


\section{Félix González Geraldino}

Sociólogo-Magister en Ciencia política y Sociología-Facultad Latinoamericana de Ciencias Sociales (FLACSO-Argentina).gonzalezgeraldino@gmail.com Orcid:0000-0002-1168-8862 